\title{
Early Man in Java
}

A COMMUNICATION by Dr. P. V. van Stein Callenfels to the Royal Anthropological Institute, which appears in summary form in Man of December, urges the desirability of reconsidering the age and standing of Pithecanthropus. Dr. Callenfels has classified the fossil fauna of the Java Pleistocene into three groups - early, middle and late Pleistocene. Among those of the early Pleistocene are Stegodon cf. prcecursor (between Tertiary prcecursor and Middle Pleistocene trigonocephalus), Hippopotamus antiquus, Leptobos, three antelopes and marine molluses, of which at least 30 per cent are extinct; Middle Pleistocene Stegodon trigonocephalus, Hippopotamus namadicus, Bos (Bubalus) bubalis paloeokarabau, Axis axis lydekkeri (abundant), Duboisia (antelope); Late Pleistocene Stegodon trigonocephalus, Hippopotamus namadicus, Bos (Bubalus) Axis axis lydekkeri (very rare), Axis axis javanicus (abundant).

By the associated fauna Pithecanthropus belongs to the Middle Pleistocene and Solo man to the late Pleistocene. In February last, however, a fossil skull of a child between one and three years was found at Modjokerto, which belongs somewhere in the line of human development. It may have been an infant Pithecanthropus. It belongs to the oldest Pleistocene. The discovery of a skull of this age necessitates raising the whole Pithecanthropus problem. No fossil fauna of the oldest Pleistocene survives into the Middle Pleistocene and it is, therefore, unlikely that the hominoid only should have survived. The Middle and Late Pleistocene have most of the animals in common, so that Solo man, known from one site only, may have existed in Middle Pleistocene times.

The records of the discovery of the femur of Pithecanthropus, which was made by Dubois himself, are known; but of the discovery of the skull-cap, which was made by a sergeant, the record has not been preserved. It is possible that the skull-cap is older than the femur. It may belong to the same stratum as the infant skull, while the femur is that of Solo man. The stone and bone artefacts discovered with Solo man clearly must belong to late Pleistocene ; but implements recently diseovered at Patjitan by Dr. G. R. H. von Konigswald, identical with Chellean and Clactonian, are so different as to suggest that they cannot have been made by the same type of man.

In this connexion attention may also be directed to a discussion by Prof. E. Dubois of Pithecanthropus and other early forms of man from Java which appears in Man of January. Prof. Dubois proceeds by setting out two propositions which he supports by argument.

Proposition I. Homo soloensis is human and protoAustralian, forming with Rhodesian man, who closely resembles Solo man, a proto-Australian group representing the most primitive type of Homo sapiens and distinet from Homo neanderthalensis, the other human species.

Wadjak man is also proto-Australian, and was described as such so long ago as 1920, though its character was recognized when it was first discovered in 1890. The distinguishing characters which determine this classification of Rhodesian man, notwithstanding its gorilloid qualities, are the pulp cavities of the teeth, the slender limb bones, the peculiar nuchal plane of the occipital bone, and the low cranial capacity, the size of the brain approaching but not quite equalling that of the Australian. The form of the torus supraorbitalis in Rhodesian man is of the type of the supraorbital ridge of the Australian rather than of the torus of Neanderthal man. The resem. blance of Solo man to Rhodesian man is most striking.

$H$. soloensis and $H$. rhodesiensis then, with Sinanthropus, are the most important of all known fossil men, as representing the most primitive type of H. sapiens. The Australian aborigine has conserved much of the primitive somatic character, especially the fundamental and, therefore, most distinctive quality of the mammalian organism, the characteristic brain volume. In the Australian (male) this may be taken as averaging 1,295 c.c. The cubic capacity of the brain of Rhodesian man has been calculated as 1,280 c.c., and for Solo man in the skull Ngandong $I$ as approximately 1,200 c.c. The protoAustralian of Ngandong and the proto-Australian of Rhodesia both had brains which were a little smaller than the brain of the Australian of to-day.

In regard to age, a very recent age is to be attributed to the deposit in which Rhodesian man was found, while fossil Solo man is of post Trinil geological age.

Proposition II. Pithecanthropus was not a man, but a gigantic genus allied to the gibbons, superior to its relatives on account of its exceedingly large brain volume, and distinguished at the same time by its erect attitude.

Decisive evidence in support is afforded by the four now femora which were recognized in the Trinil collection in 1932. Corrosion in these, by removing the superficial or periosteal bone layer, has laid bare the intermal structure of the shaft wall. This deeper shaft structure is entirely different from the human, and betrays a muscular function and a locomotion, which though facultatively erect and human-like on the ground, was also arboreal, and perhaps on uneven ground a perfection of the semi-erect gait of the gibbon. Thus this new evidence of the morphological and functional distinctnoss of Pithecanthropus furnishes proof at the same time of its close affinity with the gibbon group of anthropoid apes.

The gibbon-like appearance of Pithecanthropus is evident from the general form and many morphological details of the skull. It is evident, for example, that the gravitational centre of the head was a considerable distance in front of the condyles, and hence there was no parietal vertex of the brain, a distinctive character of man. Here Pithecanthropus agrees with chimpanzee and gibbon. The head was not poised on the vertebral column. The mandible most resembles that of the gibbon, so far as its features are anthropoid, while the strongest evidence is that given by the volume of the cerebrum, which on the law worked out by Prof. Dubois, regulating cerebral quantity in mammals, entirely confirms this second proposition.

Prof. Dubois adds a postscript dealing with the fossil child's skull discovered in February 1936, and described under the name of Homo modjokertensis. In another context it has been called "the oldest datable human fossil". In the opinion of Prof. Dubois, however, it is a child of Homo soloensis, the proof of identity being the similarity of the peculiar tympanum (see also p. 291). 